\title{
Restriction fragment length polymorphisms in isolates of Aspergillus fumigatus probed with part of the intergenic spacer region from the ribosomal RNA gene complex of Aspergillus nidulans
}

\author{
Claire L. Spreadbury, ${ }^{1}$ Brian W. Bainbridge ${ }^{2}$ and Jonathan Cohen ${ }^{1 *}$ \\ ${ }^{1}$ Infectious Diseases Unit, Departments of Bacteriology and Medicine, Royal Postgraduate Medical School, \\ Hammersmith Hospital, London W12 ONN, UK \\ ${ }^{2}$ Department of Biosphere Sciences, King's College, Kensington Campus, London W8 7AH, UK
}

(Received 19 January 1990; revised 30 April 1990; accepted 4 July 1990)

\begin{abstract}
Differences in restriction fragment length polymorphisms (RFLPs) have been detected in isolates of Aspergillus fumigatus. Genomic DNA from 11 isolates was digested with EcoRI, separated by electrophoresis, Southern blotted and probed with DNA from the intergenic spacer or non-transcribed spacer region of the rRNA gene complex of Aspergillus nidulans. Three distinct RFLP patterns were detected which differed from the control patterns observed with $A$. nidulans, Aspergillus flavus and Aspergillus niger hybridized with the same probe. Furthermore, the differences in RFLP patterns in the A. fumigatus isolates were not detected when probed with DNA coding for the rRNA complex in Saccharomyces cerevisiae. These findings may be of use in the study of the epidemiology and pathogenesis of infections caused by $A$. fumigatus.
\end{abstract}

\section{Introduction}

Aspergillus fumigatus is an ubiquitous mould in the environment and is an important nosocomial pathogen, particularly in the immunocompromised host where it is often fatal (Meyer et al., 1973). A. fumigatus infections are usually detected by standard cultural and/or histological methods. The organism is identified on the basis of its colonial morphology and characteristic microscopic features and is generally regarded as a single homogeneous species (Rippon, 1988).

The advent of molecular biology techniques has allowed a more precise examination of microbial taxonomy. Restriction endonucleases used to analyse restriction fragment length polymorphisms (RFLPs) of DNA from many species including the fungi Candida albicans (Magee et al., 1987; Matthews \& Burnie, 1989), Histoplasma capsulatum (Vincent et al., 1986) and Yarrowia lipolytica (Fournier et al., 1986) have clearly. shown distinct differences between isolates that appear morphologically identical. Gene probes based on the rRNA gene complex have been particularly useful due to their sensitivity, which is a consequence of the presence of at least 100 copies of the complex (Bell et al., 1977). In

Abbreviations: IGS, intergenic spacer; RFLP, restriction fragment length polymorphism. addition there are conserved regions which result in heterologous hybridization allowing general gene probes to be developed for a variety of unrelated organisms. It has also been shown that there are variable regions, particularly in the intergenic spacer (IGS) regions, between the $25 \mathrm{~S}$ and $18 \mathrm{~S}$ genes, which contain promoters and enhancer sequences (Tautz et al., 1987). Detection of differences between species and individual isolates may be possible using probes for these variable regions.

Recently we probed DNA from several Aspergillus species with a 6.35 kb DNA fragment coding for the rRNA complex in Saccharomyces cerevisiae and found each had a characteristic RFLP pattern (Bainbridge $e t$ al., 1990). In this study we have analysed DNA from several $A$. fumigatus strains using a DNA probe coding for a $1.2 \mathrm{~kb}$ fragment from the IGS region of the rRNA complex from Aspergillus nidulans.

\section{Methods}

Strains and DNA extraction. We studied eight clinical isolates of $A$ fumigatus (H91, H95, H111, H119, H138, H139, H171 and H201) obtained from patients at the Hammersmith Hospital, one laboratory contaminant (H170) and two strains (NCPF 2109 and 2140) from the National Collection of Pathogenic Fungi, London, UK. An isolate of A. nidulans (H102, wild-type), a clinical isolate of Aspergillus niger (H114) and a clinical isolate of Aspergillus flavus (H92) were also used. 

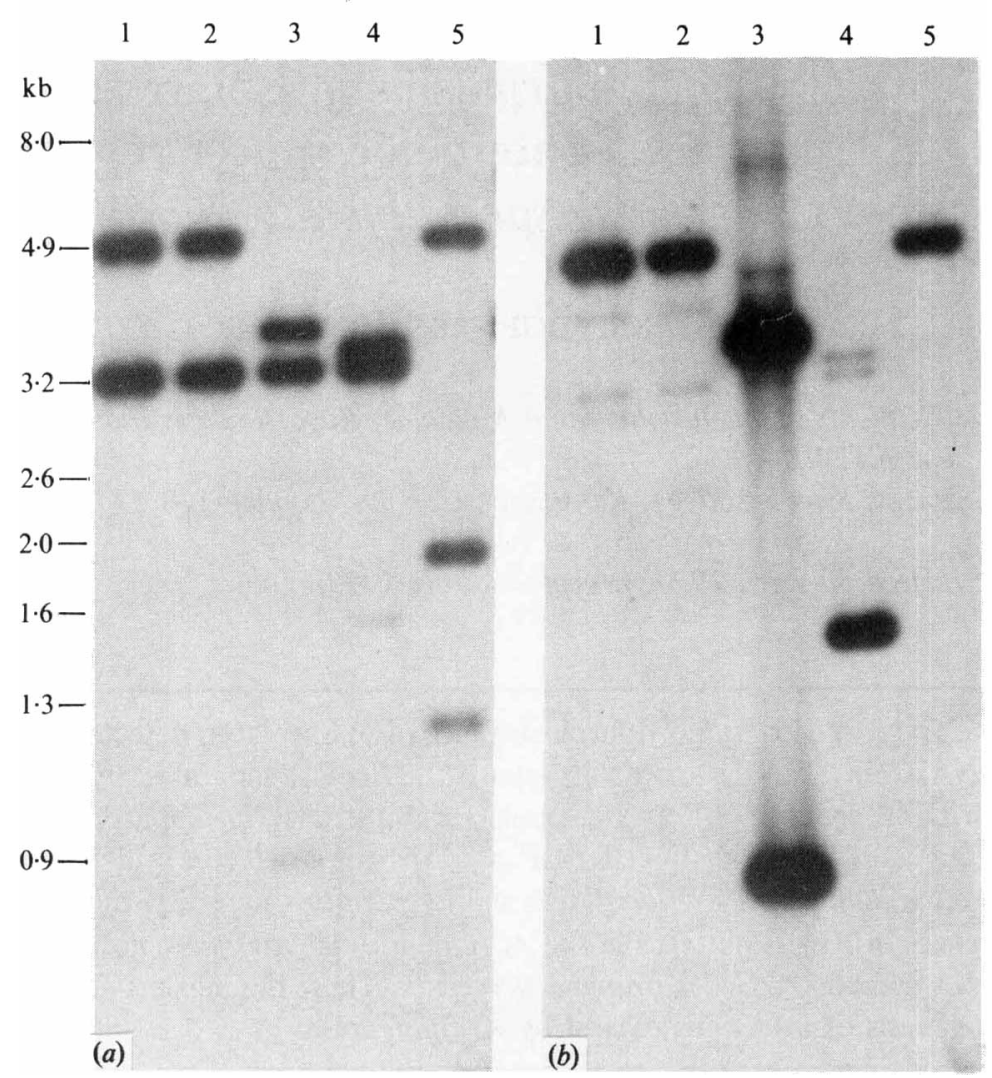

Fig. 1. Autoradiographs of Aspergillus isolates after digestion with EcoRI. Hybridization was done with the $6.35 \mathrm{~kb} S$. cerevisiae probe (a) and the $1.2 \mathrm{~kb}$ A. nidulans probe $(b)$. Lanes: 1, A. fumigatus $\mathrm{H} 95 ; 2$, A. fumigatus $\mathrm{H} 119 ; 3, A$. nidulans; $4, A$. niger; $5, A$. flavus.

Fungi were maintained on Sabouraud's media (Sab) slopes at room temperature or at $4{ }^{\circ} \mathrm{C}$. For DNA extraction conidia were inoculated onto liquid GYEP media. $\{2 \%(\mathrm{w} / \mathrm{v})$ glucose, $0 \cdot 3 \%(\mathrm{w} / \mathrm{v})$ yeast extract, $1 \%(w / v)$ peptone] and grown overnight at $37^{\circ} \mathrm{C}$. Small-scale extraction of high $M_{\mathrm{r}}$ DNA was obtained as described previously (Bainbridge et al., 1990). Briefly, the mycelia were treated with a lysis solution to degrade the cell wall, followed by deproteinization with proteinase K (Sigma) and phenol/chloroform extraction. RNA was removed by RNAase digestion and the DNA precipitated with propan2-ol. After washing and drying, the DNA pellet was dissolved in up to $50 \mu \mathrm{l}$ TE buffer and stored at $4^{\circ} \mathrm{C}$.

Analysis of DNA. All DNA samples were restricted with EcoRI (Gibco BRL) for $3 \mathrm{~h}$ at $37^{\circ} \mathrm{C}$. One gel (see Fig. 1) was prepared comprising two A. fumigatus samples (H95 and H119) and the DNA from the other three Aspergillus species. Another gel (see Fig. 2) was loaded with all of the $A$. fumigatus samples. DNA (2-3 $\mu \mathrm{g}$ per well) was loaded onto the gels and electrophoresed in $0.7 \%$ agarose overnight. Samples were run with a $1 \mathrm{~kb}$ DNA ladder $M_{\mathrm{r}}$ marker (Gibco BRL). After staining with ethidium bromide $\left(0.5 \mu \mathrm{g} \mathrm{ml}^{-1}\right)$ the gels were photographed under UV light and then transferred to nylon membranes (Amersham) by Southern blotting. The DNA was bound by UV transillumination. Gene probes were prepared from the $6.35 \mathrm{~kb}$ HindIII fragment from a recombinant plasmid SCP7 containing the ribosomal RNA gene from $S$. cerevisiae (Bell et al., 1977) and from a $1.2 \mathrm{~kb}$ Pst fragment of the pAR1 A. nidulans rRNA complex (Borsuk et al., 1982; Lockington et al., 1982). The $1.2 \mathrm{~kb}$ fragment lies entirely within the IGS region. The DNA fragments were labelled with
[32P]CTP using a random oligonucleotide kit ('Prime-a-Gene'. Stratech Scientific). The blots were prehybridized at $65^{\circ} \mathrm{C}$ for $3 \mathrm{~h}$, hybridized overnight and washed with $1 \times \mathrm{SSC} / 0.1 \% \mathrm{SDS}$ at $65^{\circ} \mathrm{C} .(1 \times \mathrm{SSC}$ is $0 \cdot 15 \mathrm{M}-\mathrm{NaCl} / 0 \cdot 015 \mathrm{M}$-trisodium citrate, $\mathrm{pH} 7 \cdot 0$ ). Autoradiographs were obtained after $3 \mathrm{~d}$ exposure. The first blot (see Fig. 1) was washed with $0 \cdot 1 \times \mathrm{SSC} / 0.1 \% \mathrm{SDS}$ at $100{ }^{\circ} \mathrm{C}$ to remove the labelled probe and hybridized with the $1.2 \mathrm{~kb} A$. nidulans spacer probe.

\section{Results and Discussion}

Genomic DNA from a range of $A$. fumigatus isolates and from $A$. nidulans, $A$. niger and $A$. flavus was extracted and analysed following digestion with $E c o$ RI. As previously reported (Bainbridge et al., 1990), the Saccharomyces probe gave distinctive RFLPs with all species and the $A$. fumigatus isolates could be distinguished readily from the other species. Differences in the degree of homology can be seen clearly as the $0.9 \mathrm{~kb}$ genomic band from $A$. nidulans hybridized strongly with the homologous $1.2 \mathrm{~kb}$ PstI probe but poorly with the $6.35 \mathrm{~kb}$ heterologous probe from $S$. cerevisiae (Fig. $1 a, b)$. Hybridization with the Saccharomyces probe revealed no differences between the two isolates of A. fumigatus (Fig. 1a). 


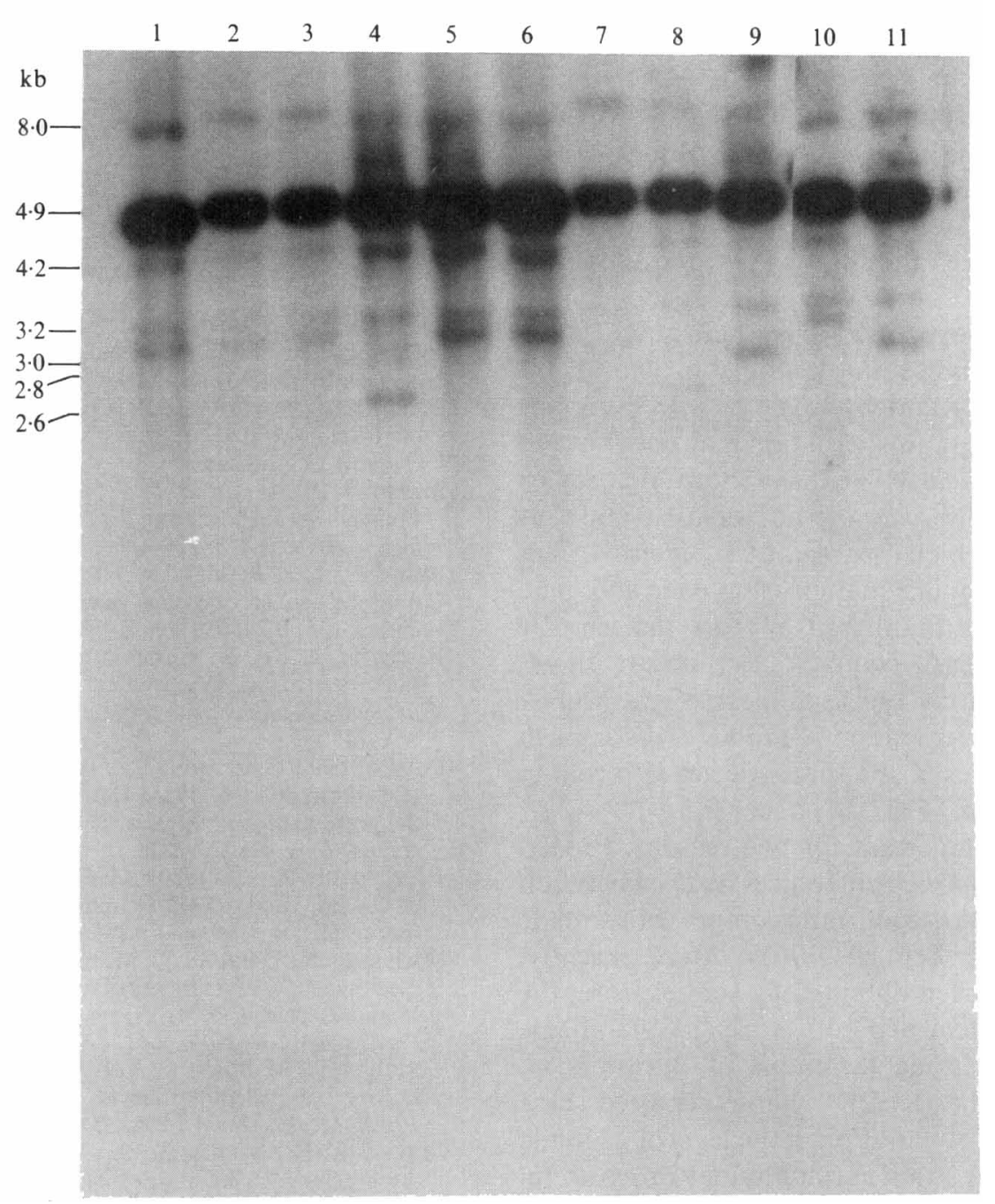

Fig. 2. Autoradiograph of 11 A. fumigatus strains hybridized with the $1.2 \mathrm{~kb}$ A. nidulans probe. Lanes: 1 , A. fumigatus strain $\mathrm{H} 91 ; 2$, H95; 3, H111; 4, H119; 5, H138; 6, H139; 7, H170; 8, H171; 9, H201; 10, NCPF 2109; 11, NCPF 2140.

In contrast, hybridization of the same blot with the $1.2 \mathrm{~kb}$ spacer probe showed clear differences in RFLPs of the A. fumigatus isolates (Fig. $1 b$ ). Three bands of $8 \cdot 0$, 4.9 and $3.2 \mathrm{~kb}$ were present in both tracks. The $3.2 \mathrm{~kb}$ fragment gave a strong signal with the $6.35 \mathrm{~kb}$ probe (Fig $1 a$ ) but a weaker signal with the $1.2 \mathrm{~kb}$ probe (Fig. 1 b). As the same blot was analysed, this was not due to differences in the amount of DNA. This observation therefore suggests that the $3.2 \mathrm{~kb}$ fragment contains only a short region of homology with the spacer probe, and that the $4.9 \mathrm{~kb}$ fragment must contain most of the spacer region. However, the $8.0 \mathrm{~kb}$ fragment (more clearly visible in Fig. 2) contains the complete rRNA complex of A. fumigatus (B. W. Bainbridge, unpublished data) and may represent incomplete digestion of the two EcoRI sites or the absence of one EcoRI site in some copies of the complex. Since this $8.0 \mathrm{~kb}$ fragment will contain the complete IGS region, homology with the probe should be strong; the weak signal obtained suggests that there were fewer copies of the $8.0 \mathrm{~kb}$ type in contrast to the more frequent $4.9 \mathrm{~kb}$ plus $3.2 \mathrm{~kb}$ type. As differences in other faint bands of $\mathrm{H} 95$ and $\mathrm{H} 119$ were observed, the analysis was extended to more isolates of $\boldsymbol{A}$. fumigatus.

Eleven $A$. fumigatus isolates were examined and three RFLP patterns were detected (Fig. 2). One pattern, designated $\mathrm{A}$, which accounted for more than half of the isolates had the common bands $8 \cdot 0,4 \cdot 9$ and $3 \cdot 2$, but in addition bands at 4.2 and $3 \mathrm{~kb}$. Pattern B, which was observed in H201 and NCPF 2140, lacked the 4.2 and $3 \mathrm{~kb}$ bands but had an extra band at $2.8 \mathrm{~kb}$. Pattern $\mathrm{C}$ (H119 and H171) shared the same basic pattern as A but the $3 \mathrm{~kb}$ band was missing and a $2.6 \mathrm{~kb}$ band was 
present. All the isolates had the 4.9 and $3.2 \mathrm{~kb}$ fragments and this appears to be the structure found in the majority of copies of the rRNA complex. The $8.0 \mathrm{~kb}$ fragment also occurs in all strains but must be present at a low copy number as discussed above. The other fragments of $4 \cdot 2$, $3.0,2.8$ and $2.6 \mathrm{~kb}$ could therefore represent copies of the complex with variable multiples of a repeat unit of approximately $200 \mathrm{bp}$.

Earlier workers have reported differences in RFLPs of fungal rRNA gene complexes by multiples of $200-400 \mathrm{bp}$ (Buckner et al., 1988) and by analogy with Xenopus (Busby \& Reeder, 1983), this variation may occur in the IGS region. Fournier et al. (1986) have shown that copies of the complex in Y. lipolytica are not identical and that these differences, which segregate at meiosis, are probably generated by unequal crossing over and gene conversion. From our findings it appears that similar variation in the rRNA complex also occurs in $A$. fumigatus. This confirms the usefulness of the rRNA gene complex for the generation of probes to distinguish between fungal isolates of the same species (Vincent $e t$ al., 1986; Magee et al., 1987).

These results are important for two reasons. Firstly, they show that intra-species differences do exist between isolates of $\boldsymbol{A}$. fumigatus, confirming observations made previously (Raper \& Fennell, 1965). More recently, support for this has been obtained by studies using the 'killer biotyping' system of Fanti et al. (1989) and the immunoblot fingerprinting technique of Burnie et al. (1989). However, the RFLP typing reported here provides direct proof of variation at the level of genomic DNA. Secondly, these strain variations may prove useful as epidemiological markers for the investigation of hospital outbreaks and may also have implications for studies of the pathogenesis of aspergillosis.

We thank the Medical Research Council, The Chest, Heart and Stroke Association, the British Society for Antimicrobial Chemotherapy and Hammersmith and Queen Charlotte's Special Health Authority for grant support. We would also like to thank Dr J. Tilburn (RPMS) for supplying us with the $A$. nidulans rRNA complex pAR1 and Dr M. Tuite (University of Kent) for the $S$. cerevisiae rRNA complex. J.C. is a Wellcome Senior Lecturer in Infectious Diseases.

\section{References}

Bainbridge, B. W., Spreadbury, C. L., Scalise, F. G. \& Cohen, J. (1990). Improved methods for the preparation of high molecular weight DNA from large and small scale cultures of filamentous fungi. FEMS Microbiology Letters 66, 113-118.

Bell, G. I., DeGennaro, L. J., Gelfand, D. H., Bishop, R. F., VALENZUELA, P. \& RUTTER, W. J. (1977). Ribosomal RNA genes of Saccharomyces cerevisiae. Journal of Biological Chemistry 252, 81188125.

Borsuk, P. A., Nagiec, M. M., StePien, P. P. \& Bartnix, E. (1982). Organization of the ribosomal RNA gene cluster in Aspergillus nidulans. Gene 17, 147-152.

BUCKNER, B., NovotNY, C. P. \& UlLRICH, R. C. (1988). Organization of the ribosomal RNA genes of Schizophyllum commune. Current Genetics 13, 417-424.

Burnie, J. P., Matthews, R. C., Clark, I. \& Milne, L. J. R. (1989). Immunoblot fingerprinting Aspergillus fumigatus. Journal of Immunological Methods 118, 179-186.

BUSBY, S. J. \& REEDER, R. H. (1983). Spacer sequences regulate transcription of ribosomal gene plasmids injected into Xenopus embryos. Cell 34, 989-996.

Fanti, F., Conti, S., Campani, L., Morace, G., Dettori, G. \& PoLONELLI, L. (1989). Studies on the epidemiology of Aspergillus fumigatus in a university hospital. European Journal of Epidemiology $5,8-14$.

Fournier, P., Gaillardin, C., Persuy, M., Klootwijk, J. \& Van HEERRIKHUIZEN, H. (1986). Heterogeneity in the ribosomal family of the yeast Yarrowia lipolytica: genomic organization and segregation studies. Gene 42, 273-282.

LoCkINGTON, R. A., TAYLOR, G. G., WinTHER, M., SCAZZOCCHIO, C., \& DAVIES, R. W. (1982). A physical map of the ribosomal DNA repeat unit of Aspergillus nidulans. Gene 20, 135-137.

MAGeE, B. B., D'SouzA, T. M. \& MAGeE, P. T. (1987). Strain and species identification by restriction fragment length polymorphisms in the ribosomal DNA repeat of Candida species. Journal of Bacteriology 169, 1639-1643.

MatTHEWS, R. \& BURNIE, J. (1989). Assessment of DNA fingerprinting for rapid identification of outbreaks of systemic candidiasis. British Medical Journal 298, 354-357.

Meyer, R. D., Young, L. S., Armstrong, D. \& Yu, B. (1973). Aspergillus complicating neoplastic disease. The American Journal of Medicine 54, 7-15.

RAPER, K. B. \& FENNELL, D. I. (1965). Aspergillus fumigatus group. In The Genus Aspergillus, 1st edn, p. 244. Baltimore: Williams \& Wilkins.

RIPPON, J. W. (1988). Aspergillus. In Medical Mycology: The Pathogenic Fungi and the Pathogenic Actinomycetes, 3rd edn, pp. 643-644. Philadelphia: W. B. Saunders.

TAUTZ, D., TAUTZ, C., WebB, D. \& Dover, G. A. (1987). Evolutionary divergence of promoters and spacers in the rDNA family of four Drosophila species: implications for molecular coevolution in multigene families. Journal of Molecular Biology 195, 525-542.

Vincent, R. D., Goewart, R., Goldman, W. E., Kobayashi, G. S., Lambowitz, A. M. \& MedofF, G. (1986). Classification of Histoplasma capsulatum isolates by restriction fragment polymorphisms. Journal of Bacteriology 165, 813-818. 